\title{
Short-term Thermal Acclimation Increases Ribulose 1, 5 Bisphosphate Carboxylase/ Oxygenase Activity and Content and Enhances Heat Stress Tolerance of Photosynthesis in Cucumber
}

\author{
Kazuyoshi NADA, Yuuichi NAgaYa and Shin HiratsuKa \\ Graduate School of Bioresources, Mie University, Tsu, Mie 514-8507, Japan
}

(Received October 13, 2020; Accepted October 30, 2020)

\begin{abstract}
We investigated whether short-term thermal acclimation (growth temperature of $38^{\circ} \mathrm{C}$ for 4 days) enhanced heat stress (leaf temperature of $45^{\circ} \mathrm{C}$ for 10 minutes) tolerance of the $\mathrm{CO}_{2}$ fixation system of photosynthesis in cucumber leaves. We found that thermal acclimation did not influence the gross photosynthetic rate (PG) or the maximum quantum yield of photosystem II ( $\mathrm{Fv} / \mathrm{Fm})$, but significantly increased the transpiration rate (TR) of the leaves. An increase in TR due to thermal acclimation increased the nitrogen and magnesium content of leaves, resulting in an increase in the content of RuBisCO. However, the activation state of RuBisCO was significantly decreased by thermal acclimation. Although the PG, Fv/Fm, and initial RuBisCO activity in non-acclimated leaves decreased significantly on heat stress, those of acclimated leaves recovered to 69,88 , and $89 \%$ of those before heat stress, respectively. Thermal acclimation maintained a high level of content and total activity of RuBisCO after heat stress, but low levels in the ratio of initial to total activity of RuBisCO. These results suggest that the quantitative intensification of $\mathrm{RuBisCO}$ by thermal acclimation makes up for its decreased activation state and leads to the recovery of photosynthetic potential after inhibition from heat stress.
\end{abstract}

Keywords : chlorophyll fluorescence, gas exchange rate, nitrogen nutrient, RuBisCO activase

\section{INTRODUCTION}

Future global temperature change, with predicted $1.5-$ $5.8{ }^{\circ} \mathrm{C}$ increases in temperatures by 2100 , will cause increased heat stress to plants and create threats to agricultural production (Rosenzweig et al., 2001). The increasing threat of temperature change is already having a substantial impact on agricultural production worldwide as heat waves cause significant yield losses posing great risks for future food security for humankind (Christensen and Christensen, 2007). The unfavorable effects of heat stress can be mitigated by developing crop plants with improved thermotolerance using an assortment of genetic approaches. For this reason, it is crucial to have a thorough understanding of the physiological responses of plants to high temperatures and their mechanisms of heat tolerance, as well as to formulate possible strategies for improving crop thermotolerance.

Photosynthesis is one of the most sensitive physiological responses in plants to heat stress. Thus, it is important to maintain high photosynthetic activity for heat stress tolerance in plants (Berry and Björkman, 1980). When plants are subjected to high temperatures, carbon dioxide $\left(\mathrm{CO}_{2}\right)$ fixation, oxygen $\left(\mathrm{O}_{2}\right)$ evolution, and photophosphorylation are restrained rapidly (Berry and Björkman, 1980). The limit of $\mathrm{CO}_{2}$ fixation by high temperature occurs simultaneously with the inactivation of ribulose 1, 5 bisphosphate (RuBP) carboxylase/oxygenase (RuBisCO) activase, which leads to the activation of RuBisCO (Feller et al., 1998; Salvucci et al., 2004). In the thylakoid membrane, the most sensitive component element to high temperature is photosystem II (PSII). Heat stress may suppress the light-absorption capacity of the plant owing to the dissolution of the $\mathrm{O}_{2}$ evolution apparatus (Mamedov et al., 1993; Nash, et al., 1985; Tompson et al., 1989).

Many studies have shown that the instantaneous response of leaf carbon exchange to temperature depends on the temperature experienced by the plant over longer time periods, a response termed temperature acclimation (Atkin et al., 2005; Atkin and Tjoelker, 2003; Berry and Björkman, 1980; Smith and Dukes, 2013; Way and Yamori, 2014; Yamori et al., 2014). Temperature acclimation can be observed through a change in the parameters that define the instantaneous temperature response curve as a result of changes previously experienced by the plant or the acclimated temperature (Atkin and Tjoelker, 2003).

Hikosaka et al. (2006) indicated that changes in the photosynthesis-temperature curve with long-term thermal acclimation are attributable to four factors: intercellular $\mathrm{CO}_{2}$ concentration, activation energy of the maximum rate of RuBP carboxylation (Vcmax), activation energy of the rate of RuBP regeneration (Jmax), and the ratio of Jmax to Vcmax. Of these, the activation energy of Vcmax may be the most important factor that influences thermal acclimation. Smith and Dukes (2017) also indicated that "fast mechanism" of thermal acclimation may be attributable to

Corresponding author : Kazuyoshi Nada, fax: +81-59-231-9587, e-mail : nada@bio.mie-u.ac.jp 


\section{K. NADA ET AL.}

activation energy of Vcmax. Therefore activation energy of Vcmax which contributes the content of RuBisCO is common important factor for both long and short term thermal acclimation.

Our previous study ( $\mathrm{Li}$ et al., 2003) indicated that, although the maximum quantum yield of PSII (Fv/Fm) in cucumber (Cucumis sativus L., cv. Suyo) leaves was subjected to extensive suppression on heat stress treatment of $45{ }^{\circ} \mathrm{C}$ leaf temperatures for 10 minutes, these suppressions were alleviated by subjecting the plants to thermal acclimation treatment at growth temperatures of $38{ }^{\circ} \mathrm{C}$ for 4 days before heat stress. This enhancement of PSII tolerance through thermal acclimation may be involved in an increased stability in the $\mathrm{O}_{2}$ evolution apparatus, along with a decrease in the unsaturation grade of the thylakoid membrane lipids ( $\mathrm{Li}$ et al., 2003). As mentioned above, it is suggested that photosynthesis improvement through thermal acclimation may induce a modification of RuBisCO. However, information on the photosynthetic response to thermal acclimation in cucumber leaves is only exhibited in PSII ( $\mathrm{Li}$ et al., 2003) and not in the $\mathrm{CO}_{2}$ fixation system.

In this study, to clarify the enhancement mechanism of heat stress tolerance by thermal acclimation, we investigated the $\mathrm{CO}_{2}$ fixation responses to thermal acclimation and heat stress in cucumber.

\section{MATERIALS AND METHODS}

Plant cultivation and the thermal acclimation treatment

Cucumber plants were germinated in the dark at $25^{\circ} \mathrm{C}$ for 2 days and then seeded onto a vermiculite tray in a glass greenhouse. When the cotyledons were fully expanded, they were transplanted into a clay pot filled with small gravel supplied with half-strength (0.5) Hoagland nutrient solution. When the first leaves were fully expanded, they were transferred to a growth chamber (FLI-301NH; EYELA, Tokyo, Japan) with $25 / 20^{\circ} \mathrm{C}$ day/night temperatures, $60 \%$ relative humidity $(\mathrm{RH})$, and a photoperiod of 14 hours illuminated at photosynthetic photon flux density (PPFD) of $150 \mu \mathrm{mol} \mathrm{m} \mathrm{m}^{-2} \mathrm{~s}^{-1}$. The thermal acclimation treatment $\left(38 / 38^{\circ} \mathrm{C}\right.$, day/night; $\left.85 \% \mathrm{RH}\right)$ was started when the second leaves were fully expanded and continued for 4 days. The second leaves were used for photosynthesis measurement after 0,2 , and 4 days of the thermal acclimation treatment and stored at $-80^{\circ} \mathrm{C}$ for $\mathrm{RuBisCO}$ analysis after photosynthesis measurement.

Photosynthetic parameter measurement in cucumber leaves before and after heat stress treatment

Heat stress treatment was conducted by dipping the aboveground plant into a water bath at $45^{\circ} \mathrm{C}$ for 10 minutes under illumination at a PPFD of $90 \mu \mathrm{mol} \mathrm{m}{ }^{-2} \mathrm{~s}^{-1}$ (Nada et al., 2020). The gas exchange rate was measured on the fully expanded second leaves before heat stress treatment using a potable gas exchange measurement system (LCA4; Shimadzu, Kyoto, Japan). The $\mathrm{CO}_{2}$ concentration and $\mathrm{RH}$ of the fully expanded second leaves (leaf area 6.25 $\left.\mathrm{cm}^{2}, 2.5 \times 8.0 \times 0.7 \mathrm{~cm}\right)$ placed in a small assimilation chamber (PLC-4; Shimadzu, Kyoto, Japan) were measured using LCA-4. The air flowing into the assimilation chamber, set at $400 \mathrm{~mL} \mathrm{~min}^{-1}$, was considered to be the atmosphere and RH was adjusted to $30 \%$ using a desiccant (Drierite, W.A. Hammond Drierite Co., Ltd., USA). The chamber temperature was set at $25{ }^{\circ} \mathrm{C}$ and the PPFD at $1,100 \mu \mathrm{mol} \mathrm{m} \mathrm{m}^{-2} \mathrm{~s}^{-1}$ using a metal halide lamp (LS-M180; Sumita Optical Glass, Inc., Japan). Net photosynthetic rate, respiration rate, stomatal conductance (GS), and transpiration rate (TR) were calculated as described by von Caemmerer and Farquhar (1981), and the gross photosynthetic rate $(\mathrm{PG})$ was calculated by adding the respiration rate and the net photosynthetic rate. Each parameter was expressed as the mean of four individuals. After heat stress treatment, the water adhering to the plant was wiped using Kimwipes (Nippon Paper Crecia Co., Ltd., Tokyo, Japan). The plant was then returned to the growth chamber at 25 ${ }^{\circ} \mathrm{C}$ and $60 \% \mathrm{RH}$ for 20 minutes. The gas exchange rate of leaves with dry surfaces was measured again at chamber temperatures of $25{ }^{\circ} \mathrm{C}$. Their effective quantum yield of PSII (ФPSII) was determined using a chlorophyll fluorometer (PAM-2000; Walz, Germany) simultaneously with gas exchange rate under PPFD of $1,100 \mu \mathrm{mol} \cdot \mathrm{m}^{-2} \cdot \mathrm{s}^{-1}$. To measure the maximum quantum yield of PSII ( $\mathrm{Fv} / \mathrm{Fm})$, leaves were dark-acclimated using a leaf clip holder for 30 minutes before the first gas-exchange measurement. The $\mathrm{Fv} / \mathrm{Fm}$ value was determined at the end of the first gasexchange measurement. Subsequently, the leaves underwent dipping treatment for heat stress for 10 minutes with a leaf clip holder, followed by induction processing at $25{ }^{\circ} \mathrm{C}$ for 20 minutes (i.e., dark-acclimated for 30 minutes); Fv/Fm was determined again before the second gasexchange measurement. Each parameter is expressed as the mean of four individuals.

Ribulose 1, 5 biphosphate carboxylase/oxygenase activity and content analysis in cucumber leaves

Three leaf discs $(\phi 1.5 \mathrm{~cm})$ were obtained before and after the dipping treatment of the leaves that had been used to measure gas exchange and chlorophyll fluorescence, and were immediately placed in liquid nitrogen $(\mathrm{N})$, and stored at $-80^{\circ} \mathrm{C}$ for analysis of $\mathrm{RuBisCO}$ activity. The residual leaf $(1 \mathrm{~g})$ was stored at $-30^{\circ} \mathrm{C}$ for RuBisCO content analysis.

RuBisCO activity was analyzed based on the method described by Nada et al. (2020). To measure the initial activity of $\mathrm{RuBisCO}$, leaf discs stored at $-80^{\circ} \mathrm{C}$ were ground in liquid $\mathrm{N}$, to which extraction buffer $[100 \mathrm{mM}$ Tricine-potassium hydroxide $(\mathrm{KOH})(\mathrm{pH} 7.8), 5 \mathrm{mM}$ dithiothreitol (DTT), $5 \mathrm{mM}$ magnesium chloride $\left(\mathrm{MgCl}_{2}\right)$, $1 \mathrm{mM}$ disodium ethylenediaminetetraacetic acid $\left(\mathrm{Na}_{2}-\right.$ EDTA), $0.2 \%$ bovine serum albumin $(\mathrm{BSA})(\mathrm{w} / \mathrm{v})], 0.5$ $\mathrm{mM}$ PMSF, and $20 \%$ PVPP (w/v) were added, and the sample was immediately mixed using a $23 \mathrm{M}$ electric mixer (As-One, Osaka, Japan). The sample was filtered using a miracloth (Millipore; Darmstadt, Germany) and then centrifuged (at $4^{\circ} \mathrm{C}$ and $2,500 \times g$ for 30 seconds). The supernatant and analysis buffer $[100 \mathrm{mM}$ Tricine-KOH $(\mathrm{pH}$ 7.8), $5 \mathrm{mM}$ DTT, $20 \mathrm{mM} \mathrm{MgCl} 2,1 \mathrm{mM} \mathrm{Na} 2$-EDTA, $5 \mathrm{mM}$ potassium chloride $(\mathrm{KCl})], 2.5 \mathrm{mM}$ ATP, $10 \mathrm{mM}$ sodium bicarbonate $\left(\mathrm{NaHCO}_{3}\right), 0.2 \mathrm{mM}$ nicotinamide adenine dinu- 
cleotide (NADH), $5 \mathrm{mM}$ Creatin-P, $1.2 \mathrm{mM}$ RuBP, $6.4 \mathrm{U}$ GAPDH, 9.0 U PGK, and $20 \mathrm{U}$ PCK were mixed and the attenuation rate was measured at $340 \mathrm{~nm}$ using a spectrophotometer (UV-1200; Shimadzu, Japan) at $25^{\circ} \mathrm{C}$. The time required to add the extraction buffer solution at the beginning of measuring absorbance was almost $180 \mathrm{sec}$ onds. For measurement of the total activity of RuBisCO, the residual of the supernatant in the first extraction was again centrifuged at $4^{\circ} \mathrm{C}$ and $10,000 \times g$ for 10 minutes, after which the analysis buffer, except RuBP, was added to it and the solution was incubated in a spectrophotometer at $25^{\circ} \mathrm{C}$ for 2 minutes. The attenuation rate at $340 \mathrm{~nm}$ was measured by adding RuBP $(1.2 \mathrm{mM})$. The initial and total activity of $\mathrm{RuBisCO}\left(\mu \mathrm{mol} \cdot \mathrm{m}^{-2} \cdot \mathrm{s}^{-1}\right)$ was expressed as the mean of four individuals.

RuBisCO content was analyzed based on the method described by Nada et al. (2020). Leaves $(1 \mathrm{~g})$ stored at -30 ${ }^{\circ} \mathrm{C}$ were ground in liquid $\mathrm{N}$ using a pestle. Proteins were extracted on ice using an extraction buffer $(100 \mathrm{mM}$ sodium phosphate buffer $\mathrm{pH} 7.0,2 \mathrm{mM} \mathrm{MgCl}, 1 \mathrm{mM} \mathrm{Na}_{2}-$ EDTA, $12.5 \%$ glycerol, $1 \%$ 2-mercaptoethanol), $0.1 \mathrm{mM}$ PMSF, and $20 \%$ PVPP (w/v). The solution was centrifuged at $10,000 \times g$ for 10 minutes at $4^{\circ} \mathrm{C}$. Then, $40 \mu \mathrm{L}$ of Laemmli buffer [100 mM Tris-hydrochloride $(\mathrm{HCl}), \mathrm{pH}$ $6.8,4 \%$ sodium dodecyl sulphate (SDS) (w/v), $12 \% 2$ mercaptoethanol (v/v), $20 \%$ glycerol (v/v), $0.2 \%$ BPB] and $8 \mu \mathrm{L}$ of 2 -mercaptoethanol were added to $40 \mu \mathrm{L}$ of protein extracts, and heated at $100^{\circ} \mathrm{C}$ for 5 minutes. After cooling to room temperature, $10 \mu \mathrm{L}$ of the sample was loaded onto an SDS-polyacrylamide gel (resolving gel, $12.5 \%$ polyacrylamide; stacking gel, $4.5 \%$ polyacrylamide) filled with electrophoresis buffer (25 mM Tris, $192 \mathrm{mM}$ glycine, $0.1 \%$ SDS (w/v)). Electrophoresis was performed using power supply equipment (CONSTAPOWER 3500; ATTO, Japan). An electric current was set at $20 \mathrm{~mA}$ in the stacking gel and at $40 \mathrm{~mA}$ in the resolving gel. After electrophoresis, the gel was stained using the Coomassie brilliant blue (CBB) solution [0.1 \% CBBR250 (w/v), $25 \%$ methanol (v/v), $7 \%$ acetic acid (v/v)]. After decoloring treatment, bands of $55 \mathrm{kDa}$, which corresponded to the large subunit of RuBisCO, were photographed using FAS III (Toyobo, Japan), and quantified using NIH-Image (free software). The RuBisCO content ( $\mathrm{mg} \mathrm{g}^{-1} \mathrm{FW}$ ) was expressed as the mean of four individuals.

\section{Mineral content analysis}

For potassium (K), magnesium (Mg), and phosphorus (P) analysis, organic matter was removed from the dry matter of leaves using the dry-ashing method. The freezedried, fully expanded, second leaves were ground to a powder, after which $100 \mathrm{mg}$ of leaf powder was placed in a magnetic plate and heated at $550^{\circ} \mathrm{C}$ in a muffle furnace for 10 hours. Thereafter, $5 \mathrm{~mL}$ of $6 \mathrm{~N}$ hydrochloric acid $(\mathrm{HCl})$ was added to the magnetic plate and evaporated to dryness on a hot plate set to $180^{\circ} \mathrm{C}$. Then, $5 \mathrm{~mL}$ of $1 \mathrm{~N} \mathrm{HCl}$ was added to the dried matter and warmed on the hot plate for 10 minutes. The solution thus produced (ashing solution) was sealed tightly and stored. One milliliter of the ashing solution was added to $2 \mathrm{~mL}$ of lanthanum chloride solution
(La: 25,000 ppm) and its $\mathrm{K}$ and $\mathrm{Mg}$ content was measured using atomic absorption spectrometry (AA-6200; Shimadzu, Japan). For measurement of $\mathrm{P}$ content, $5 \mathrm{~mL}$ of the ashing solution was mixed with $5 \mathrm{~mL}$ of the coloring reagent vanadomolybdate-nitric acid, after which the absorbance of the mixture was measured at $430 \mathrm{~nm}$ using a spectrophotometer (UV-1200; Shimadzu, Japan). The K, $\mathrm{Mg}$, and $\mathrm{P}$ content per dry weight ( $\mathrm{mg} \mathrm{g}^{-1} \mathrm{DW}$ ) was calculated using a standard curve derived from the absorbance of each ion standard solution and expressed as a mean of four individuals.

Nitrogen analysis was performed using the Kjeldahl method. Leaf powder (100 mg) was placed in a Kjeldahl flask to which $4 \mathrm{~mL}$ sulfuric acid was added. The Kjeldahl flask was placed in a fume hood overnight. Then, the Kjeldahl flask was incubated at $440^{\circ} \mathrm{C}$ for 4 minutes using a Digesdahl digestion apparatus (Hach, USA), after which $10 \mathrm{~mL}$ of hydrogen peroxide $\left(\mathrm{H}_{2} \mathrm{O}_{2}\right)$ was added to it and the mixture was heated again for 1 minutes. After cooling to room temperature, the pyrolysis liquid in the Kjeldahl flask was diluted to $100 \mathrm{~mL}$ using distilled water. Then, 25 g diluting solution and $4 \mathrm{~mL}$ of $40 \%$ sodium hydroxide $(\mathrm{NaOH})$ were put in a distillatory apparatus and distilled for $8 \mathrm{~min}$. Ammonia $\left(\mathrm{NH}_{3}\right)$ that was obtained from distillation was titrated using dilute sulfuric acid. The $\mathrm{N}$ content per gram of dry weight ( $\mathrm{mg} \mathrm{g}^{-1} \mathrm{DW}$ ) was calculated based on the titration value and expressed as the mean of four individuals.

\section{Statistical analysis}

The data were analyzed using the Excel statistics software (Esumi, Japan). Significant differences $(P<0.05)$ among treatments were determined using the Tukey-Kramer test.

\section{RESULTS}

Photosynthetic parameters, RuBisCO activity and content, and mineral content in cucumber leaves after thermal acclimation.

Although the PG, Fv/Fm, and ФPSII of thermally acclimated and non-acclimated leaves did not differ significantly, the TR and GS of thermally acclimated leaves were significantly higher compared to those of non-acclimated leaves (Table 1). The initial activity of RuBisCO also showed no significant difference in between thermally acclimated and non-acclimated leaves, whereas the total activity of thermally acclimated leaves was significantly higher compared to that of non-acclimated leaves. The ratio of initial to total activity in non-acclimated leaves was higher than $90 \%$, but that of thermally acclimated leaves decreased significantly. The RuBisCO content showed the same tendency as total activity, i.e., it increased after thermal acclimation treatment.

The $\mathrm{N}$ content of non-acclimated leaves increased once on $2 \mathrm{~d}$, but returned to the level before the treatment on $4 \mathrm{~d}$, whereas that of acclimated leaves also increased on $2 \mathrm{~d}$ of the thermal acclimation treatment and remained at a high level for the duration of the treatment (Table 2). The $\mathrm{K}$ content of thermally acclimated leaves was lower than 


\section{K. NADA ET AL.}

Table 1 Gross photosynthetic rate (PG), transpiration rate (TR), and stomatal conductance (GS), maximum quantum yield (Fv/Fm), and effective quantum yield (ФPSII) of photosystem II, initial and total activity, ratio of initial to total activity, and content of ribulose 1, 5 biphosphate carboxylase/oxygenase (RuBisCO) in thermally acclimated and non-acclimated leaves before heat stress treatment.

\begin{tabular}{|c|c|c|c|c|c|c|c|c|c|c|}
\hline \multirow{2}{*}{$\begin{array}{l}\text { Temperature } \\
\text { of treatment }\end{array}$} & \multirow{3}{*}{$\begin{array}{l}\text { Days of } \\
\text { treatment }\end{array}$} & \multirow{2}{*}{ PG } & \multirow{2}{*}{ TR } & \multirow{2}{*}{ GS } & \multirow{2}{*}{$\mathrm{v} / \mathrm{Fm}$} & \multirow{2}{*}{ DPSII } & \multicolumn{3}{|c|}{ Rubisco activity } & \multirow{3}{*}{$\begin{array}{l}\text { Rubisco } \\
\text { content } \\
\mathrm{mg} \cdot \mathrm{g}^{-1} \mathrm{FW}\end{array}$} \\
\hline & & & & & & & Initial & Total & Initial/Total & \\
\hline${ }^{\circ} \mathrm{C}$ & & $\mu \mathrm{mol} \cdot \mathrm{m}^{-2} \cdot \mathrm{s}^{-1}$ & $\mathrm{mmol} \cdot \mathrm{m}^{-2} \cdot \mathrm{s}^{-1}$ & $\mathrm{~mol} \cdot \mathrm{m}^{-2} \cdot \mathrm{s}^{-1}$ & & & \multicolumn{2}{|c|}{$\mu \mathrm{mol} \cdot \mathrm{m}^{-2} \cdot \mathrm{s}^{-1}$} & $\%$ & \\
\hline 25 & 0 & $21.48 \pm 0.63 \mathrm{a}$ & $3.50 \pm 0.29 \mathrm{a}$ & $0.506 \pm 0.029 \mathrm{a}$ & $0.787 \pm 0.001 \mathrm{a}$ & $20 \pm 0.008 \mathrm{a}$ & $\pm 0.78 \mathrm{a}$ & 23.99 & $92.47 \pm$ & 14.23 \\
\hline 25 & 2 & $20.05 \pm 0.90 \mathrm{a}$ & $3.35 \pm 0.28 \mathrm{a}$ & $0.510 \pm 0.021 \mathrm{a}$ & $0.788 \pm 0.011 \mathrm{a}$ & $0.490 \pm 0.012 \mathrm{a}$ & $22.53 \pm 1.12 \mathrm{a}$ & $24.67 \pm 1.09 \mathrm{a}$ & $92.08 \pm$ & $0.37 \mathrm{a}$ \\
\hline 38 & 2 & $21.39 \pm 0.53 \mathrm{a}$ & $5.45 \pm 0.12 b$ & $1.074 \pm 0.037 \mathrm{~b}$ & $0.804 \pm 0.003 \mathrm{a}$ & $0.524 \pm 0.008 \mathrm{a}$ & $22.88 \pm 0.59 \mathrm{a}$ & $31.70 \pm 1.22 \mathrm{~b}$ & $72.35 \pm 2$ & $19.68 \pm 0.48 \mathrm{~b}$ \\
\hline 25 & 4 & $18.83 \pm 0.65 \mathrm{a}$ & $3.67 \pm 0.33 \mathrm{a}$ & $0.668 \pm 0.020 \mathrm{a}$ & $0.791 \pm 0.008 \mathrm{a}$ & $0.489 \pm 0.017 \mathrm{a}$ & $21.16 \pm 0.62 \mathrm{a}$ & $22.86 \pm 0.53 \mathrm{a}$ & $92.70 \pm 3.71 \mathrm{~b}$ & $13.20 \pm 0.17 \mathrm{a}$ \\
\hline 38 & 4 & $20.57 \pm 0.77 \mathrm{a}$ & $5.90 \pm 0.30 \mathrm{~b}$ & $1.229 \pm 0.072 \mathrm{~b}$ & $0.800 \pm 0.001 \mathrm{a}$ & $0.472 \pm 0.017 \mathrm{a}$ & $20.74 \pm 1.62 \mathrm{a}$ & $31.84 \pm 2.42 \mathrm{~b}$ & $65.30 \pm 3.75 \mathrm{a}$ & $17.83 \pm 0.54 \mathrm{~b}$ \\
\hline
\end{tabular}

Different letters indicate significant differences at $P<0.05$ using Tukey-Kramer's test.

Table 2 Mineral contents in thermal acclimated and non-acclimated leaves.

\begin{tabular}{|c|c|c|c|c|c|}
\hline $\begin{array}{c}\text { Temperature of } \\
\text { treatment } \\
{ }^{\circ} \mathrm{C}\end{array}$ & $\begin{array}{l}\text { Days of } \\
\text { treatment }\end{array}$ & $\begin{array}{l}\text { Nitrogen } \\
\text { content } \\
\mathrm{mg} \cdot \mathrm{g}^{-1} \mathrm{DW}\end{array}$ & $\begin{array}{l}\text { Potassium } \\
\text { content } \\
\mathrm{mg} \cdot \mathrm{g}^{-1} \mathrm{DW}\end{array}$ & $\begin{array}{l}\text { Magnesium } \\
\text { content } \\
\mathrm{mg} \cdot \mathrm{g}^{-1} \mathrm{DW}\end{array}$ & $\begin{array}{l}\text { Phosphrus } \\
\text { content } \\
\mathrm{mg} \cdot \mathrm{g}^{-1} \mathrm{DW}\end{array}$ \\
\hline 25 & 0 & $40.20 \pm 0.58 \quad \mathrm{a}$ & $33.46 \pm 0.30 \mathrm{~b}$ & $9.12 \pm 0.29 \quad \mathrm{a}$ & $22.81 \pm 0.18$ \\
\hline 25 & 2 & $45.60 \pm 1.15 \mathrm{~b}$ & $35.77 \pm 0.58 \mathrm{~b}$ & $10.88 \pm 0.17 \mathrm{~b}$ & $16.80 \pm 0.92$ \\
\hline 38 & 2 & $49.28 \pm 0.61 \mathrm{c}$ & $33.46 \pm 1.16 \mathrm{~b}$ & $11.76 \pm 0.25 \mathrm{~b}$ & $23.41 \pm 0.18$ \\
\hline 25 & 4 & $37.22 \pm 0.29 \mathrm{a}$ & $34.04 \pm 0.59 \mathrm{~b}$ & $10.88 \pm 0.06 \quad b$ & $12.05 \pm 0.68$ \\
\hline 38 & 4 & $47.93 \pm 0.22 \mathrm{bc}$ & $29.42 \pm 0.84 \quad \mathrm{a}$ & $12.94 \pm 0.09 \mathrm{c}$ & $15.6 \pm 0.75$ \\
\hline
\end{tabular}

Different letters indicate significant differences at $P<0.05$ using Tukey-Kramer's test.

that of non-acclimated leaves, but the difference was small. The Mg content of thermally acclimated leaves was higher than that of non-acclimated leaves during the treatment. The $\mathrm{P}$ content of thermally acclimated leaves gradually decreased during treatment, but was significantly higher than that of non-acclimated leaves.

Effects of the thermal acclimation treatment on responses of photosynthetic parameters to heat stress in cucumber leaves

The PG of non-acclimated leaves was severely decreased in plants exposed to heat stress of $45^{\circ} \mathrm{C}$ for 10 minutes, but that of thermally acclimated leaves on $4 \mathrm{~d}$ of treatment recovered to $69 \%$ of that before the heat stress (Fig. 1). Heat stress did not have an influence on the TR and GS of both thermal-acclimated and non-acclimated leaves. Heat stress reduced both Fv/Fm and ФPSII of nonacclimated leaves to $28 \%$ of those at pre-stress treatment (Fig. 2). Thermal acclimation treatment alleviated the depression effect of heat stress on $\mathrm{Fv} / \mathrm{Fm}$ and ФPSII, and restored them to 88 and $81 \%$ of that before the heat stress, respectively. The initial activity of RuBisCO in non-acclimated leaves decreased to $46 \%$ by heat stress and remained almost the same during treatment, whereas that of thermally acclimated leaves on $4 \mathrm{~d}$ of treatment recovered to $89 \%$ of that before the heat stress (Fig. 3). The total activity and content of RuBisCO in both thermally acclimated and non-acclimated leaves did not have an influence on heat stress, i.e., these values were approximately equal to those before heat stress. The ratio of initial to total activity of RuBisCO in both thermally acclimated and non-acclimated leaves decreased to about $50 \%$ by heat stress and remained the same during treatment.

\section{DISCUSSION}

In the photosynthetic responses to heat stress in cucumber leaves, $\mathrm{PG}$ and $\mathrm{Fv} / \mathrm{Fm}$ decreased to 13 and 28 $\%$, respectively, due to heat stress at leaf temperature $45^{\circ} \mathrm{C}$ for 10 minutes (Fig. 1, 2). These severe inhibitions by heat stress were alleviated by thermal acclimation at a growth temperature of $38^{\circ} \mathrm{C}$ for 4 days. The $\mathrm{PG}$ and $\mathrm{Fv} / \mathrm{Fm}$ recovered to 69 and $88 \%$ of those before exposure to heat stress, respectively. The photosynthetic enhancement of heat tolerance in cucumber was also confirmed by the $\mathrm{O}_{2}$ evolution rate and the electron transport rate of PSII and PSI using the $\mathrm{O}_{2}$ electrode method (Li et al., 2003). Li et al. (2003) also indicated that thermal acclimation induced stabilization of the thylakoid membrane by increasing its lipid saturation, thus resulting in the enhancement of heat tolerance of photosystem in cucumber.

Smith and Duked (2017) indicated that the thermal acclimation of photosynthesis occurred by changing the temperature only at 7 days (i.e., fast mechanisms) when provided with high levels of water and $\mathrm{N}$. The plant cultivation conditions in the present research were appropriate to allow "the fast mechanisms" function. In addition, it was observed that the decrease in a nutrient solution in thermally acclimated seedlings was faster than that in nonacclimated seedlings. The reason for this phenomenon seems to be an increase in absorption of a nutrient solution with an increase in TR of thermally acclimated leaves (Table 1). As a result, the mineral nutrient status of thermally acclimated leaves was progressive, i.e., $\mathrm{N}$ and $\mathrm{Mg}$ content of thermally acclimated leaves was higher than that of nonacclimated leaves (Table 2).

We found that PG, Fv/Fm, and $\Phi$ PSII did not differ 

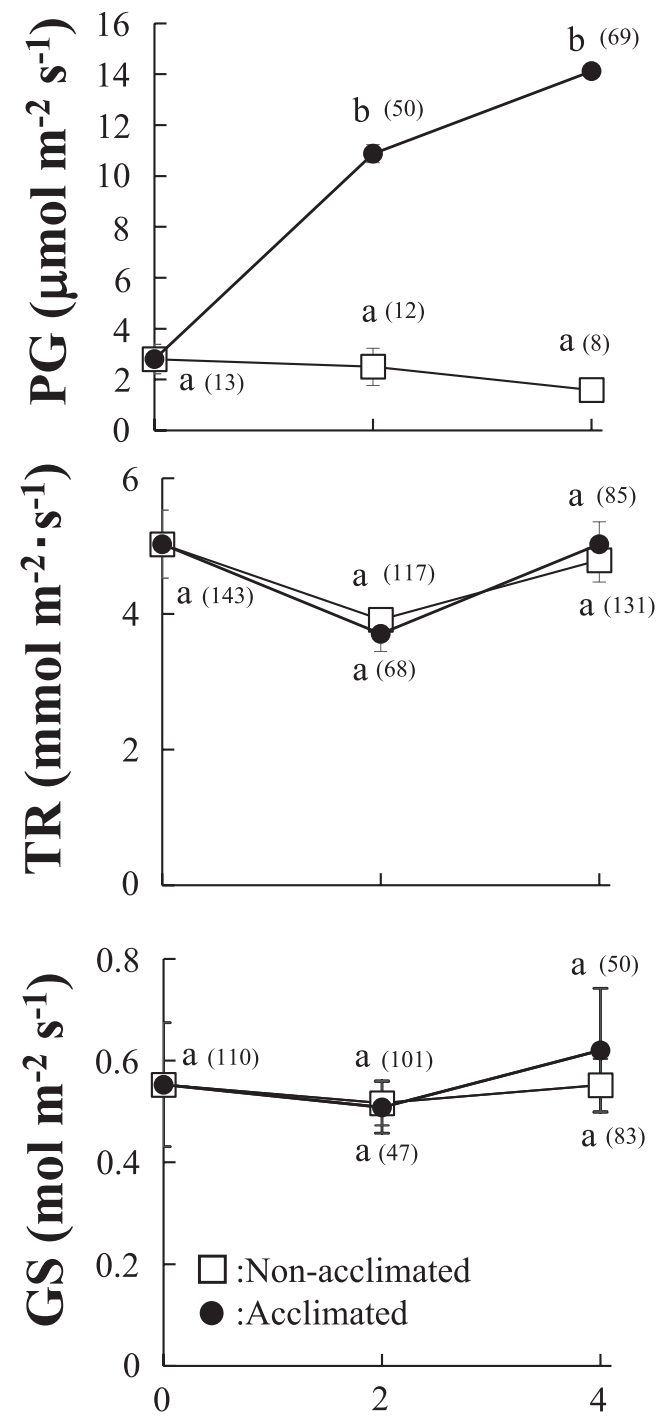

\section{Days of acclimation treatment}

Fig. 1 Effect of the heat stress on photosynthetic rate (PG), transpiration rate (TR), and stomatal conductance (GS) of thermally acclimated (close circle) and non-acclimated (open square) leaves. The values in the figure indicate the ratio of each plot to that before the heat stress. Different letters indicate significant differences at $P<0.05$ (Tukey-Kramer test).

significantly between thermally acclimated and non-acclimated leaves (Table 1). Our previous research indicates that the photosynthetic parameters in cucumber leaves do not decrease even at growth temperatures of $40^{\circ} \mathrm{C}$ because of a decrease in leaf temperatures with an increase in TR. The thermal acclimation temperature of $38^{\circ} \mathrm{C}$ was within the temperature range studied in the previous research and did not decrease the photosynthetic function of cucumber leaves. The total activity and content of RuBisCO in thermally acclimated leaves increased significantly compared to that in non-acclimated leaves (Table 1). This could be related to the increase in $\mathrm{N}$ content of leaves (Table 2). Hikosaka et al. (2006) have indicated that the activation energy of Vcmax is the most important factor for longterm thermal acclimation of photosynthesis. Smith and Dukes (2017) have also suggested that "fast mechanism"
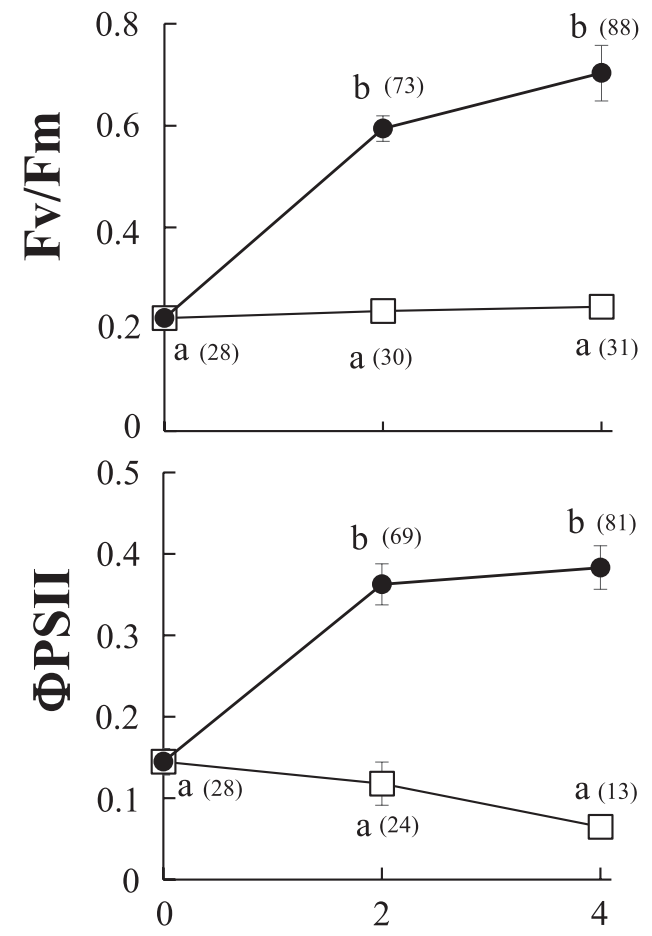

\section{Days of acclimation treatment}

Fig. 2 Effect of the heat stress on maximum quantum yield (Fv/Fm), and effective quantum yield (ФPSII) of thermally acclimated (close circle) and non-acclimated (open square) leaves. The values in the figure indicate the ratio of each plot to that before the heat stress. Different letters indicate significant differences at $P<0.05$ (Tukey-Kramer test).

of thermal acclimation may be attributable to activation energy of Vcmax, which contributes the total activity and content of RuBisCO. Therefore, it may be important for the increase in heat tolerance that thermal acclimation enhance RuBisCO synthesis, as shown in the present research. Thermal acclimation had a negative effect on the initial activity of RuBisCO in spite of an increase in total activity, implying that the activation state of RuBisCO (i.e., activity of RuBisCO activase; Salvucci and CraftsBrandner, 2004) decreased during thermal acclimation treatment, as shown by the decrease in the ratio of initial to total activity (Table 1). After heat stress treatment, the ratio of initial to total activity remained at a low level in both thermally acclimated and non-acclimated leaves; however, initial activity increased only in thermally acclimated leaves. These results suggest that the quantitative intensification of RuBisCO by thermal acclimation makes up for a functional decline of RuBisCO activase and leads photosynthetic potential to recover from the inhibition of heat stress.

We propose that the enhancement of heat tolerance in photosynthesis by thermal acclimation in cucumber leaves occurs due to the stabilization of the thylakoid membrane by an increase in its lipid saturation, as shown by Li et al. (2003), and by the quantitative intensification of RuBisCO with an increase in $\mathrm{N}$ content of leaves, as shown in this research. The prerequisite for a thermal acclimation 

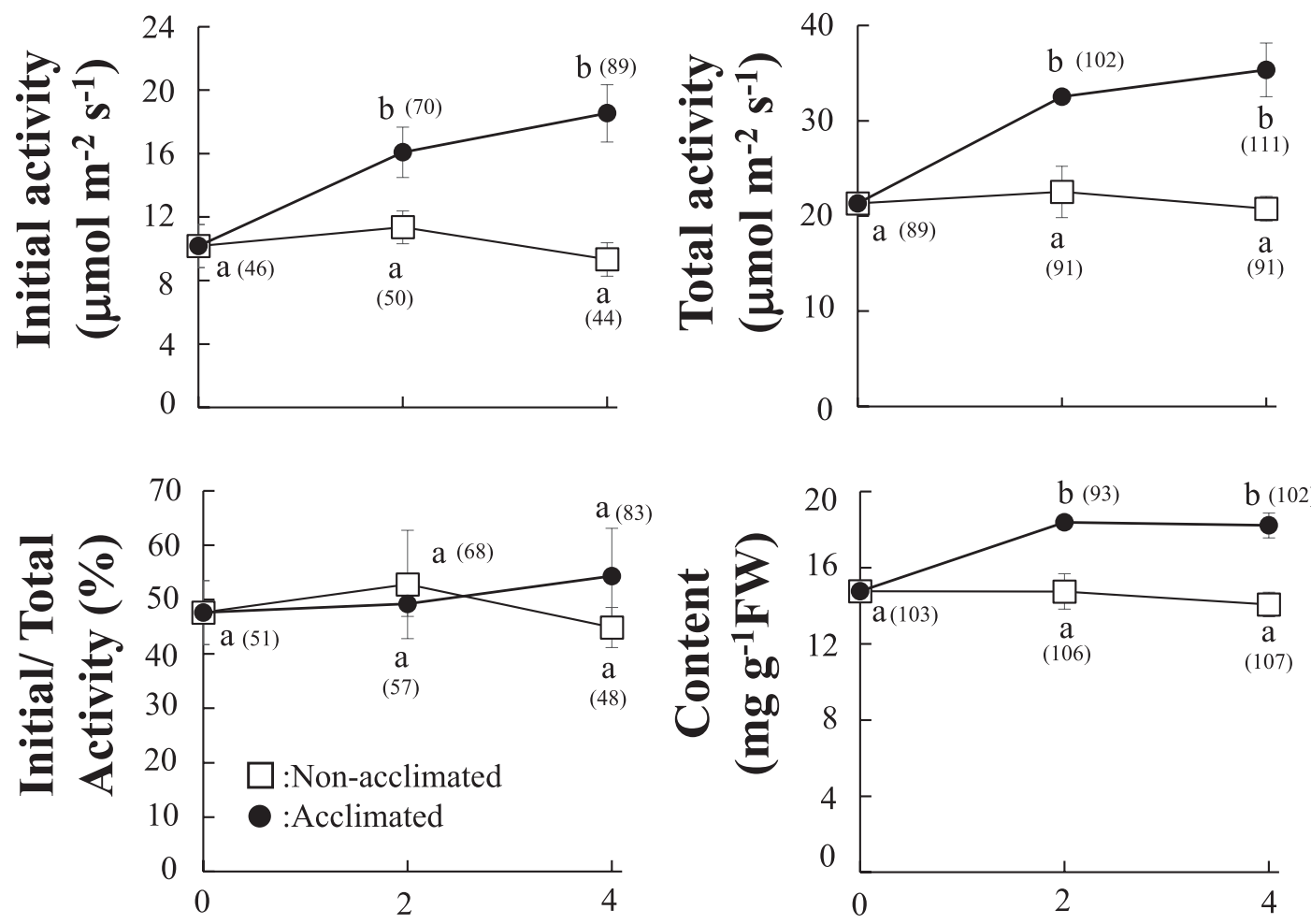

\section{Days of acclimation treatment}

Fig. 3 Effect of the heat stress on initial and total activity, ratio of initial to total activity, and content of ribulose 1, 5 biphosphate carboxylase/oxygenase (RuBisCO) in thermally acclimated (close circle) and non-acclimated (open square) leaves. The values in the figure indicate the ratio of each plot to that before the heat stress. Different letters indicate significant differences at $P<0.05$ (Tukey-Kramer test).

response is the presence of high levels of water and $\mathrm{N}$ (Smith and Dukes, 2017); however, these conditions are not necessarily guaranteed under natural conditions. Therefore, we should accumulate information on tolerance mechanisms in plants against multiple stresses, e.g., high temperature, water stress, and deficit of $\mathrm{N}$.

\section{ACKNOWLEDGEMENTS}

We would like to express our sincere gratitude to Satoshi Mukoh and Masato Mitsune for their great contribution in this research. We would like to thank Editage (www.editage.com) for English language editing.

\section{REFERENCES}

Atkin, O. K., Bruhn, D., Hurry, V. M., Tjoelker, M. G. 2005. The hot and cold: unravelling the variable response of plant respiration to temperature. Funct. Plant Biol. 32: 87-105.

Atkin, O. K., Tjoelker, M. G. 2003. Thermal acclimation and dynamic response of plant respiration to temperature. Trends Plant Sci. 8: 343-351.

Berry, J., Björkman, O. 1980. Photosynthetic response and adaptation to temperature in higher plants. Annu. Rev. Plant Physiol. 31: 491-543.

Christensen, J. H., Christensen, O. B. 2007. A summary of the PRUDENCE model projections of changes in European climate by the end of this century. Clim. Change 81: 7-30.

Feller, U., Crafts-Brandner, S. J., Salvucci, M. E. 1998. Moder- ately high temperatures inhibit ribulose-1, 5-bisphosphate carboxylase/oxygenase (Rubisco) activase-mediated activation of Rubisco. Plant Physiol. 116: 539-546.

Gunderson, C. A., O'hara, K. H., Campion, C. M., Walker, A. V., Edwards, N. T. 2010. Thermal plasticity of photosynthesis: the role of acclimation in forest responses to a warming climate. Glob. Chang. Biol. 16: 2272-2286.

Hikosaka, K., Ishikawa, K., Borjigidai, A. Muller, O., Onoda, Y. 2006. Temperature acclimation of photosynthesis: mechanisms involved in the changes in temperature dependence of photosynthetic rate. J. Exp. Bot. 57: 291-302.

Li, Z., Nada, K., Tachibana, S. 2003. High-temperature-induced alteration of ABA and polyamine contents in leaves and its implication in thermal acclimation of photosynthesis in cucumber (Cucumis sativus L.). J. Jpn. Soc. Hort. Sci. 72 393-401.

Mamedov, M., Hayashi, H., Murata, N. 1993. Effects of glycinebetaine and unsaturation of membrane lipids on heat stability of photosynthetic electron-transport and phosphorylation reactions in Synechocystis PCC6803. Biochem. Biophys. Acta 1142: 1-5.

Nada, K., Mukoh, S., Hiratsuka, S. 2020. Evaluation of photosynthetic responses to heat stress in cucumber leaf treated by dipping into heating water under illuminated condition. J. Sci. High Technol. Agric. 32: 214-220.

Nash, D., Miyao, M., Murata, N. 1985. Heat inactivation of oxygen evolution in photosystem II particles and its acceleration by chloride depletion and exogenous manganese. Biochim. Biophys. Acta 807: 127-133.

Rosenzweig, C., Iglesias, A., Yang, X. B., Epstein, P. R., Chivian, E. 2001. Climate change and extreme weather events. Implica- 


\section{THERMAL ACCLIMATION OF RuBisCO}

tions for food production, plant diseases and pests. Glob. Chang. Hum. Health 2: 90-104.

Salvucci, M. E., Crafts-Brandner, S. J. 2004. Inhibition of photosynthesis by heat stress: the activation state of Rubisco as a limiting factor in photosynthesis. Physiol. Plant. 120: 179-186.

Smith, N. G., Dukes, J. S. 2013. Plant respiration and photosynthesis in global-scale models: incorporating acclimation to temperature and $\mathrm{CO}_{2}$. Global Change Biol. 19: 45-63.

Smith, N. G., Dukes, J. S. 2017. Short-term acclimation to warmer temperature accelerates leaf carbon exchange processes across plant types. Global Change Biol. 23: 4840-4853.

Tompson, L. K., Blaylock, R., Sturtevant, J. M., Brudvig, G. W 1989. Molecular basis of the heat denaturation of photosys- tem II. Biochemistry 28: 6686-6695.

von Cammerer, S., Farquhar, G. D. 1981. Some relationships between the biochemistry of photosynthesis and the gas exchange of leaves. Planta 153: 376-387.

Way, D. A., Yamori, W. 2014. Thermal acclimation of photosynthesis: on the importance of adjusting our definitions and accounting for thermal acclimation of respiration. Photosyn. Res. 119: 89-100.

Yamori, W., Hikosaka, K., Way, D. A. 2014. Temperature response of photosynthesis in $\mathrm{C} 3, \mathrm{C} 4$, and CAM plants: temperature acclimation and temperature adaptation. Photosyn. Res. 119: 101-117. 
